\title{
Associative asymmetry in paired associates
}

EILEEN W. COUTU

NORWICH HOSPITAL, NORWICH, CONNECTICUT

Pairs of trigrams were presented in the usual anticipatory manner, except that the second member of each pair consisted of two items, $B$ and $C$. On the delayed recall test, the association tested for symmetry was that between B and C. For ward association was found to be superior to backward association, indicating that equal availability of terms may not be sufficient for symmetrical associations

Asch \& Ebenholtz (1962) have shown that the usual paired-associate learning procedures result in the $B$ term, which $\mathrm{S}$ must recall from memory, being more available than the $A$ term, which $S$ generally recites upon presentation. When equal availability of $\mathrm{A}$ and $\mathrm{B}$ was obtained, the association between the terms was found to be symmetrical. The results of their work suggested that the superiority of forward association in previous experiments was due to the lack of availability of the $\mathrm{A}$ term for recall, rather than the relative strengths of the association in either direction. Subsequent studies have offered support for a theory of associative symmetry (Horowitz \& White, 1965; Horowitz, Brown, \& Weissbluth, 1964).The learning paradigm used in the present experiment requires $S$ to try to recall $B$ and $\mathrm{C}$ from memory when $\mathrm{A}$ is presented. The availability of $\mathrm{B}$ and $\mathrm{C}$ should remain equal during learning, thus the association between them should be symmetrical during testing.

\section{Procedure}

Ss were 48 female students from the $\mathrm{S}$ pool at the University of Connecticut.

Trigrams having a $53 \%$ association value on the Glaze (1928) list were randomly arranged into eight A-BC pairs. Pairs were avoided that appeared to have obvious associations when the $\mathrm{BC}$ terms were in either the $\mathrm{BC}$ or $\mathrm{CB}$ orders. Varying the arrangement and order of the $\mathrm{B}$ and $\mathrm{C}$ trigrams resulted in four lists. In two lists the $\mathrm{B}$ and $\mathrm{C}$ trigrams were arranged as one term (WYKDUP) and in the remaining lists they were arranged as two terms (WYK DUP). While the A member of each pair remained the same, the order of the trigrams making up the second terms was balanced so that the BC order was used for half of the lists and the $\mathrm{CB}$ order for the other half. A Gerbrand's memory drum was used to present the lists.

During learning, the A term was shown for 3 sec., followed immediately by a 3-sec. exposure of the BC (or CB) term. Three different sequences of pair presentations were used. Ss pronounced the trigrams aloud. Following the 16th learning trial, $\mathrm{S}$ was given a number puzzle with instructions that she would have $1 \mathrm{~min}$. to arrange the numbers in descending order. At the end of that minute, $\mathrm{S}$ was tested for recall of the $\mathrm{B}$ and $\mathrm{C}$ tri- grams under an unaided recall (UR) condition or an aided recall (AR) condition. For the UR test, 16 Ss were asked to recite as many trigrams as possible from the association task. The remaining Ss were tested by presenting each of the $16 \mathrm{~B}$ and $\mathrm{C}$ trigrams at a 3-sec. rate. Each $\mathrm{S}$ was told that she would be shown one of the two response trigrams at a time and that she was to recite the missing trigram. The sequence of forward and backward testing of the $\mathrm{BC}$ or $\mathrm{CB}$ items was balanced across Ss. Results

The task of learning the A-BC pairs proved to be too difficult for most $S s$ to do in the number of trials allowed. The mean number of pairs correct on the last learning trial was only 2.50 for the UR Ss and 2.28 for the AR Ss. As the difference of .22 is not significant $(t<1.00)$, the Ss may be considered equal in the level of learning achieved.

On the delayed recall tests, Ss recalled on the average, 8.35 trigrams. A Lindquist (1953) Type III analysis of variance showed that the procedural manipulations of the arrangement and order of the stimuli did not interact with effects of trigram position on the recall of $B$ and $\mathrm{C}$ on the delayed test. The order of trigrams will be ignored in the remaining analyses; all references to the $\mathrm{BC}$ term include both $\mathrm{BC}$ and $\mathrm{CB}$.

The effects of the recall conditions (UR and AR) and the position of the $B$ and $C$ trigrams (left and right) were analyzed using a Lindquist Type I design. Recall conditions had no significant effect on the total number of trigrams recalled, the means being 9.06 and 8.22 for the UR and AR conditions, respectively $(F<1.00)$.

Ss demonstrated superior recall of trigrams presented on the right in the $\mathrm{BC}$ term. The mean number of right trigrams recalled was 4.73 , while the mean number of left trigrams was $3.77(F=18.37, \mathrm{df}=1 / 46$, $p<.001)$. The interaction between recall and position, which represents a comparison of the trigrams recalled in the left and right positions by the UR Ss with the backward and forward recall of the AR Ss, was significant $(F=13.13, \mathrm{df}=1 / 46, \mathrm{p}<.001)$. Under the UR condition the mean number of left trigrams recalled was 4.63 and the mean number of right trigrams was 4.44 . By comparison, under the AR condition the respective means were 3.34 and 4.88. Therefore, while the trigrams were equally available for recall, Ss were superior in forward recall.

To see if there was a relationship between the learning and testing trials, the responses made during learning and testing by the $\mathrm{AR}$ Ss were classified for each $\mathrm{BC}$ term as both correct (left and right), left-only, or right-only. All B and C trigrams were counted, including those that were given in response to the wrong $A$ term 
in learning. The number of left-only trigrams recalled on the learning trials was greater than the number of right-only trigrams recalled. A correlated test across Ss showed that the difference in means was significant $(t=3.11, d f=32, p<.01)$, suggesting that left trigrams may have been more available than right trigrams at the end of learning.

Inspection of the data suggested that during testing certain BC terms were more likely to be recalled in both directions than others. The null hypothesis that there is no difference in the probability of each $\mathrm{BC}$ term being recalled symmetrically by AR Ss was rejected by a chi-square test at the .005 level $\left(X^{2}=20.31\right.$, $d f=7$ ). In contrast to the AR Ss, it was noted that for the UR Ss there was no difference in the probability of each $\mathrm{BC}$ term being recalled completely during testing $\left(X^{2}=5.50\right.$, df $\left.=7, p>.25\right)$.

The eight $\mathrm{BC}$ terms were ranked according to the number of times they had been recalled completely during learning and then according to the number of times they had been recalled symmetrically during testing by AR Ss. A Kendall's tau showed that the agreement between the rankings was significant and substantial $(\mathrm{T}=.71, \mathrm{p}<.01)$.

\section{Discussion}

The data do not support a hypothesis of associative symmetry. The learning paradigm produced equal availability of the $B$ and $C$ trigrams as measured by the UR conditions. If the frequency of recall during learning is considered a measure of availability, the left trigrams in the BC terms were favored over the right trigrams. Depending upon the measure of availability used, Ss should have performed equally well in the forward and backward directions or should have been superior in backward recall. As Ss did significantly better in the forward direction, it would appear that the availability of the left term is not always sufficient to produce backward recall when an association between the two terms has been formed.

Symmetrical recalls appeared to be related to the number of whole responses given during learning. It may be that symmetry in association can be achieved only when the association is either easy to learn, overlearned, or both. The results of the present experiment suggest that further research, testing the association between $\mathrm{B}$ and $\mathrm{C}$, would show that asymmetry predominates during learning.

\section{References}

Asch, S. E., \& Ebenholtz, S. M. The principle of associative symmetry. Proc. Amer. Phil. Soc., 1962, 106, 135-163.

Glaze, J. A. The association of nonsense syllables. $J$. genet. Psychol., 1928, 35, 255-267.

Horowitz, L. M., Brown, Z. M., \& Weissbluth, S. Availability and the direction of associations. J. exp. Psychol., 1964, 68, 541549.

Horowitz, L. M., \& White, M. A. Producing symmetrical associations. Paper read at American Psychological Association, Chicago, Sept., 1965.

Lindquist, E. F. Design and analy sis of experiments in psychology and education. Boston: Houghton Mifflin, 1953. 